\title{
O PROFESSOR COMO UM POLICY MAKER: O CON- TEXTO DA PRODUÇÃO DE TEXTO EM UM PROJETO DE INTERNACIONALIZAÇÃO DO CONHECIMENTO PARA ALUNOS DE ENSINO MÉDIO DE UMA ESCO- LA TECNOLÓGICA'
}

Glenda Heller Cáceres

(IFRS)

\section{RESUMO}

Neste trabalho, buscamos mostrar a trajetória da construção de textos produzidos por ocasião de um projeto de internacionalização do conhecimento, arquitetado para estudantes do Ensino Médio de uma escola tecnológica. Trata-se de um estudo de caso orientado pela teoria das políticas linguísticas educativas que focalizam o papel do professor como agente da microesfera escolar (MENKEN; GARCÍA, 2010) e pela metodologia de análise do Ciclo de Políticas (BALL; BOWE, 1992). As análises permitem visualizar o modo como as políticas linguísticas (ações coletivas, dinâmicas e conflituosas) podem ser encabeçadas e conduzidas por um professor que é hierarquicamente inferior, em termos da função institucional que exerce, aos seus interlocutores.

PALAVRAS-CHAVE: políticas linguísticas educativas; agentividade; professor; Ciclo de Políticas.

\section{Contextualização}

Dentro do paradigma epistemológico interpretativista, este estudo de caso visa a compreender o papel do professor como um policy maker (MENKEN; GARCÍA, 2010) inserido na micropolítica escolar (BALL, 2009), por meio da análise de parte de um processo político-linguístico: 
o Contexto da Produção de Texto para a promoção da internacionalização e aprendizagem de língua espanhola em contexto tecnológico no Ensino Médio².

O processo político-linguístico de que falamos teve origem em um Instituto Federal (doravante, IF) numa época em que alguns movimentos reivindicatórios dos professores da área de Ciências Humanas e Sociais fizeram despertar nos professores de Letras (línguas e literatura) o desejo de rediscutir e redirecionar seu próprio lugar na instituição.

O contexto imediato, o institucional, estava claramente influenciado por políticas educacionais públicas de âmbito nacional, como o Programa Ciência Sem Fronteiras (CSF), a Lei 11.161/2005, a Lei 11.684/20083', entre outros. Contudo, nessa arena de disputas institucionais, um professor (autora da pesquisa e deste artigo) - ator social fundamental da esfera escolar, uma vez que ocupa uma posição intermediária entre gestores e alunos -, começa a submergir num emaranhado de questionamentos sobre o seu fazer docente, especialmente sobre "como é (ou como deve ser) o ensino-aprendizagem de espanhol como língua adicional numa escola tecnológica, para alunos de Ensino Médio".

Essa indagação inicial levou-nos a refletir sobre políticas de aquisição (COOPER, 1989) e agir, dentro do âmbito educativo escolar, propondo um projeto pedagógico de internacionalização do ensino. Tal projeto consistia em promover um intercâmbio estudantil para os alunos de uma turma de Ensino Médio, a fim de que estes pudessem vivenciar, entre outros aspectos, o uso da língua em imersão e a aprendizagem de tópicos específicos de sua área de formação técnica, uma vez que a escola anfitriã deveria ser, igualmente, tecnológica. Isso porque acreditávamos que essa experiência incidiria nas práticas linguísticas de nossos alunos (e nas suas relações com as línguas), além de instigar reflexões de ordem social e cultural, fundamentais para a sua formação como indivíduos.

Todavia, a proposta pedagógica teve de passar por várias instâncias dentro da instituição e contou com a colaboração de um grupo de atores sociais (diretores, professores, técnicos administrativos e alunos). Aqui, buscamos responder às seguintes perguntas:

- Quando se iniciou a construção dos textos da política e quem participou dessa construção?

- Houve intenção de buscar consensos na produção dos textos e esse objetivo foi alcançado? 
- Quais são as ideias predominantes nos textos construídos e que propósitos e valores elas representam?

Desde já, elucidamos que nossas perguntas partem de algumas asserções. E essas asserções estão fundamentadas nos dados gerados pela pesquisa que foram selecionados para serem estudados como um caso. Logo, ao falarmos de "textos" na questão um e subsequentes, estamos supondo que o processo político-linguístico em análise gerou, além do texto inicial, pelo menos um texto secundário. Ademais, em sendo o nosso interesse centrar as análises no papel do professor, previamente damos por sabido que um dos atores que participa da produção de tais textos é o próprio professor-educador. Comecemos, então, pela questão do educador como um agente de políticas linguísticas.

\section{Políticas linguísticas educativas: o agente professor}

As políticas linguísticas ${ }^{4}$ não nascem na esfera educativa de ensino formal. Como uma área de estudos, emergem da gestão de situações de plurilinguismo, especificamente em países que deixaram de ser colonizados no início do século XX e que passavam por um processo de reestruturação de sua governança (KAPLAN; BALDAUF JR, 1997). Ainda dessa época (1950-1960), são remanescentes estudos que priorizam as políticas de amplitude nacional, como as típicas políticas top down - quer dizer, que vêm do topo (em termos da hierarquia de exercício do poder) em direção às bases.

Com os avanços dessa área de estudos, percebeu-se que nem toda a política linguística é planejada e executada consciente e linearmente, das autoridades aos subalternos, do nacional ao local. Notou-se, ainda, que a estrutura social, econômica e política não são rígidas de forma tal que impeçam o deslocamento dos indivíduos, os quais seriam inertes, portanto, às forças do sistema. Os atores sociais - atualmente - são vistos como agentes de políticas linguísticas, com capacidade de criá-las e transformá-las, tanto quanto investigadores da área ou governantes. $\mathrm{O}$ reposicionamento dos agentes políticos faz com que haja um olhar mais direcionado às micropolíticas de tipo bottom up.

Quando se entende que as políticas não estão compostas apenas por leis nacionais, quando se observa que tais políticas não são um bloco monolítico, mas processos dinâmicos e quando o ator social "de base" ganha destaque no fazer político-linguístico, entram em cena as diversas instâncias pelas quais se deslocam os movimentos que constituem as políticas 
linguísticas. Dessa maneira, tanto a escola adquire um lugar de prestígio nas investigações quanto os professores que dela fazem parte.

Em geral, quando unimos escola e línguas, estamos diante de políticas de aquisição (COOPER, 1989), sobretudo se tais políticas estão vinculadas ao aumento no número de usuários de determinada língua. Esse papel tem sido cumprido pela escola há séculos no mundo todo, desde o ensino das línguas clássicas até o ensino das línguas chamadas modernas. Do mesmo modo, a manutenção de uma língua já aprendida ou a reaquisição de uma língua perdida são políticas linguísticas de aquisição. Mas nem só do ensino de línguas constitui-se o que entendemos por políticas linguísticas educativas.

A escolha das línguas a serem ofertadas na escola, as atitudes de professores e alunos diante dessas línguas, os discursos que circulam no espaço institucional sobre elas, as formas de avaliar tais línguas ou os materiais usados para ensiná-las também são exemplos de políticas linguísticas educativas. Parece, portanto, que o ambiente institucional é o ponto central daquilo que se denomina "políticas linguísticas educativas", incluídas aí as práticas linguísticas que tomam forma nas instituições de ensino.

O dinamismo das políticas é um elemento enfatizado na obra de BALL (2009), que afirma que, para analisá-las é necessário, de antemão, admitir que elas estão em constante movimento. Vamos, então, tentar compreender como o autor coloca seu ponto de vista a respeito das políticas educativas para, depois, podermos traçar uma análise do nosso caso de políticas linguísticas educativas.

\section{A abordagem do Ciclo de Políticas: contexto da produção de textos}

Segundo Ball (2009), a política pode ser entendida de três modos: a) como regulações e imperativos (forças que agem para mudar o comportamento das pessoas); b) como uma construção de princípios e valores (num sentido mais filosófico); c) como um esforço coletivo com múltiplos níveis de interpretação e tradução. $\mathrm{Na}$ verdade, diz o autor, a política é tudo isso simultaneamente, mas confessa estar afiliado à terceira concepção. Desta, inferimos que o esforço coletivo significa que as políticas nunca são obra de um ator social, mas de um grupo deles, os quais podem ter funções diferentes e não atuar, necessariamente, todos ao mesmo tempo. Quanto a interpretação e tradução, são termos usados pelo 
autor para representar os significados de tais políticas (sobretudo a respeito dos textos), que serão talvez tantos quanto o número de pessoas que as interpretam. São, inicialmente, a compreensão da política e, em seguida, os encaminhamentos práticos que são dados a ela.

$\mathrm{O}$ autor tenta ainda afastar-se da concepção tradicional de políticas, a qual as considera algo linear e ordenado, unidirecional em seu movimento. Essa maneira de entender as políticas faz presumirmos que seu significado é transparente, quando, ao contrário, trata-se de um campo de conflitos e lutas multifacetadas, quer dizer, com diferentes valores, interesses e significados (BALL, 2009). Para o autor, as políticas são instáveis, não são claras e são, no mais das vezes, contraditórias. O fato de o mundo das políticas ser iterativo e não linear, diz o autor, torna a tarefa do ator social incrivelmente desafiadora.

Tendo essa compreensão das políticas, Ball e Bowe, em 1992, propõem um método para analisá-las. Tal método, denominado Ciclo de Políticas $(\mathrm{CP})$, está em construção permanente, conforme esclarece o próprio Ball (2009). Além disso, há de se ter em conta que o CP não é uma descrição da política ou uma teoria sobre ela, mas um instrumento que deve facilitar a sua compreensão. Tomaremos o texto de Mainardes ${ }^{5}$ (2006) para explicar a proposta do CP.

O CP está composto de cinco contextos. Um deles é o Contexto da Influência, que se refere a um conjunto de elementos que incidem na formulação das políticas. No nosso caso, como dissemos na seção de contextualização, são, por exemplo, o programa CSF e as citadas Leis. Isso quer dizer que as influências não são necessariamente de textos, mas de programas, grupos de interesses comuns, grandes corporações etc. Essas influências podem se dar mais localmente ou advir de atores e organismos internacionais. O Contexto da Influência é "onde normalmente as políticas públicas são iniciadas e os discursos políticos são construídos" e "é também nesse contexto que os conceitos adquirem legitimidade e formam um discurso de base para a política" (MAINARDES, 2006, p. 20).

Diretamente relacionado ao Contexto da Influência está o Contexto da Produção de Texto, que é o que nos interessa de momento, pois será explorado na análise dos dados. Os textos produzidos podem ser orais e escritos, oficiais e não oficiais. Podem ser, além disso, vídeos, pronunciamentos, comentários sobre outros textos etc. Conforme informa Mainardes (2006), os textos políticos resultam de acordos entre interesses muitas vezes conflituosos, já que produtores de texto diferentes competem para 
controlar determinadas situações políticas. Além disso, os próprios textos podem ser contraditórios, conter ideias ambíguas ou vagas.

Já o Contexto da Prática vem a ser o lugar das respostas aos textos produzidos. Nesse contexto, emergem os efeitos ou consequências da interpretação das políticas iniciais. Isso quer dizer que as políticas não são simplesmente a transposição do texto para a ação tal como este prevê, mas serão aquilo que se interpreta e se traduz de tais textos. Por isso, Ball (2009) fala da "ação criativa" que existe na transição entre o Contexto da Produção de Texto e o Contexto da Prática. A "ação criativa" nada mais é do que a recontextualização dos textos, a ressignificação dada por seus leitores/agentes. Nesse sentido, o autor nega que as políticas sejam simplesmente implementadas.

O Contexto da Prática, no entanto, não deve ser confundido com o Contexto de Resultados (ou Efeitos). Aqui, encontramos os impactos da prática ou, dito de outra maneira, são as implicações que emanam das práticas, aquilo que por meio delas foi transformado. É importante analisar os impactos em seu conjunto; ver, objetivamente, quais respostas provêm do Contexto da Prática, pois, tomados em separado, tais efeitos podem comprometer o entendimento da política como um todo (MAINARDES, 2006).

Por fim, o Contexto da Estratégia é uma proposta de Stephen Ball, baseada na teoria crítica e em ideias foucaultianas de tentar minimizar desigualdades sociais que possam ter sido criadas por uma política. Para isso, é necessário identificar estratégias e criar atividades que intervenham nessa realidade. O Contexto da Estratégia, contudo, não está desvinculado dos demais contextos.

O CP não tem uma direção única e, na medida em que as políticas são dinâmicas e vão mudando, alguns contextos podem estar inseridos em outros contextos (BALL, 2009). Por exemplo, dentro do Contexto da Prática, pode haver um Contexto de Produção de Texto, o qual pode, por sua vez, levar a outros Contextos de Prática. A não linearidade permite que instâncias macro e micro sejam perfeitamente relacionáveis (e isso, como dissemos, é inclusive desejável).

Percebemos, assim, uma proximidade entre as perspectivas de políticas linguísticas educativas propostas por Menken e García (2010) e da análise metodológica de políticas educativas de Ball (2009). Para o estudo de caso que apresentamos aqui, optamos por analisar apenas o Contexto de Produção de Texto do já citado projeto pedagógico de internacionaliza- 
ção do conhecimento. A fim de que o leitor possa compreender melhor os dados de nosso recorte de pesquisa, trataremos disso brevemente a seguir.

\section{Apresentação e significação dos dados do estu- do de caso}

Fundamentando-nos em preceitos do estudo de caso (cfe. STAKE, 2003), apresentamos um esquema (Tabela 1) que pretende facilitar o entendimento de nosso objeto de análise.

\begin{tabular}{|c|c|}
\hline \multicolumn{2}{|c|}{$\begin{array}{l}\text { O caso: produção de textos para uma experiência de intemacionalizaçào do } \\
\text { conhecimento }\end{array}$} \\
\hline Instituições parceiras & $\begin{array}{l}\text { IF [brasileiro] e Escola Agrária (EA) } \\
\text { [argentina] }\end{array}$ \\
\hline $\begin{array}{l}\text { Atores envolvidos diretamente na } \\
\text { produção dos textos }\end{array}$ & $\begin{array}{l}\text { Professor proponente (P -IF) e Diretor (D - } \\
\text { EA) }\end{array}$ \\
\hline Interlocuçào da produçào & Internet (e-mails) \\
\hline Textos & $\begin{array}{l}\text { Projeto pedagógico (PP); Convênio, Termo } \\
\text { Aditivo (TA) }\end{array}$ \\
\hline Periodo de redaçào dos textos & $18 / 06 / 2014$ a $15 / 10 / 2014$ \\
\hline
\end{tabular}

Tabela 1. Contextualização do caso no que concerne ao Contexto da Produção de Texto.

Fonte: 0 autor.

O fluxograma (Figura 1) da elaboração dos três textos citados na Tabela 1 compreende o ponto de partida da elaboração dos textos, que começa no primeiro quadro superior esquerdo, e estende-se ao final das negociações dos documentos em pauta, representado no primeiro quadro superior direito. Isso quer dizer que a leitura das ações em ordem cronológica deve seguir a linha que une os diferentes episódios, começando no alto do canto esquerdo. Não foi possível, dada a escolha do critério "Contexto da Produção de Texto", mostrar as várias outras ações dessa política linguística educativa que foram levadas a cabo simultaneamente ao processo de construção de textos, mas a linha que perpassa os quadros mostra que essa política está em movimento (BALL, 2009). 
O tamanho desigual dos quadros que compõem a figura é proposital e indica que os debates e decisões não têm o mesmo peso, em termos de valores e interesses, para os atores que negociam as políticas ${ }^{6}$. Já o sombreamento de alguns quadros busca salientar as ações relevantes para nossa identidade como professora-educadora que atua como um policy maker nessa política linguística educativa (sobretudo na construção dos textos) e, consequentemente, na arena de disputas (MENKEN; GARCÍA, 2010). Por fim, os tópicos salientados em negrito revelam a avaliação das negociações por parte de seus interlocutores.

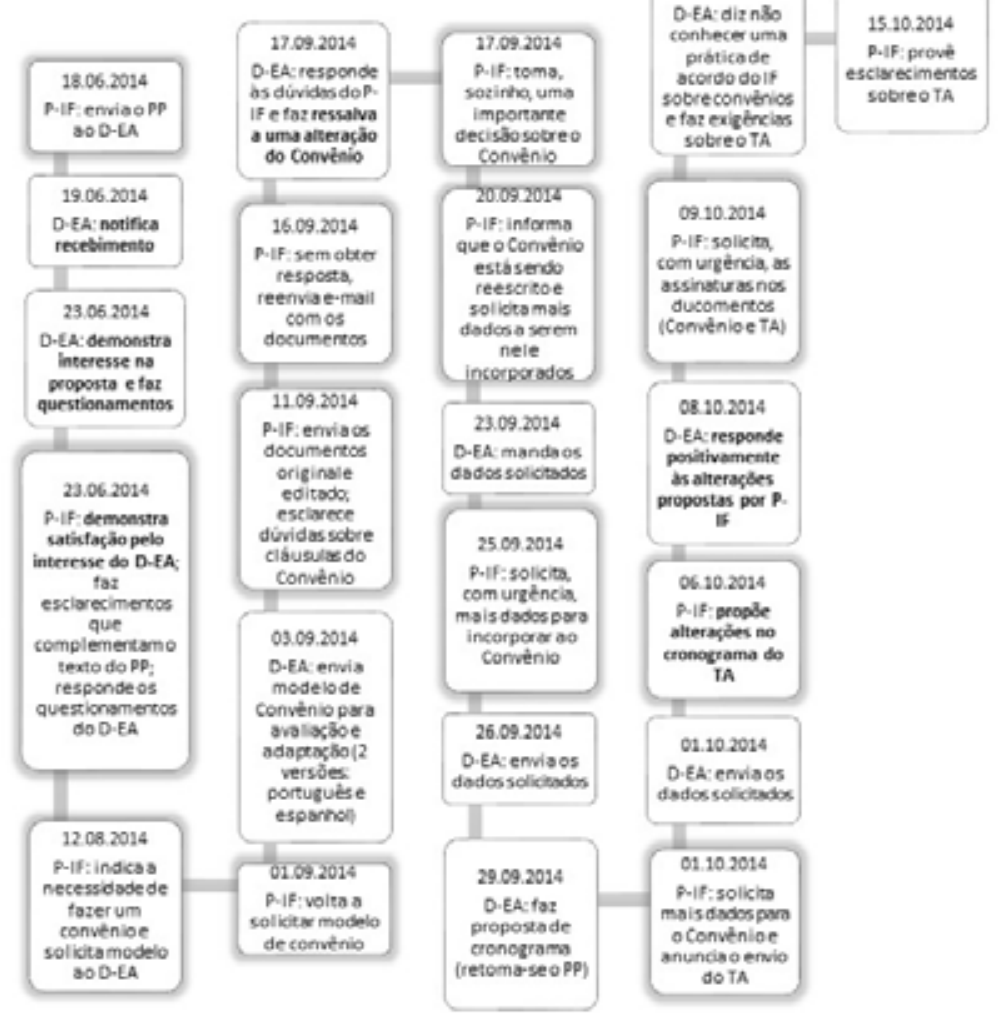

Figura 1. Fluxograma dos trâmites de elaboração e consolidação dos textos referentes ao Projeto Pedagógico, Convênio interinstitucional e Termo Aditivo.

Fonte: 0 autor 
A seguir, trataremos mais destes três aspectos da elaboração dos textos políticos: o papel do professor como um agente fundamental da agenda político-linguística; as avaliações, disputas e negociações (do P-IF e do D-EA) em torno dos textos; e, ainda, o próprio tecer dos textos.

\section{Entre textos: as negociações da política linguís- tico-educativa e a atuação do professor como um po- licy maker no Contexto da Produção de Textos (CPT) ${ }^{7}$}

Comecemos por observar que a iniciativa da proposta de internacionalização é, em nosso caso, um ato individual. Aproximamo-nos do ambiente escolar desejado (uma escola técnica, como é aquela em que trabalhamos), cercando seu representante máximo, o D-EA, e propomos-lhe, diretamente, o intercâmbio educativo. A proposta é feita por meio da apresentação de um texto - também elaborado por nós - que consiste no Projeto Pedagógico. Este é, então, o ponto de partida do CPT, bem como da política linguística educativa de que faz parte o caso que estamos analisando. ${ }^{8}$

Nesse contexto, chama-nos atenção o modo como o P-IF e o D-EA avaliam o conteúdo dos textos iniciais da construção política (tanto os textos dos documentos quanto aqueles produzidos pelos interlocutores sobre esses mesmos textos). Vejamos, por exemplo, como avaliam a proposta do intercâmbio educativo, materializado no PP, começando pelo posicionamento do D-EA:

He estado analizando tu propuesta y me parece muy interesante. ${ }^{9}$ (excerto de e-mail, 19 jun 2014)

Estimado profesor: hemos estado analizando tu propuesta con más detenimiento y la verdad es que nuestra institución está muy interesada en concretar el intercambio que nos propones. ${ }^{10}$ (excerto de e-mail, 23 jun 2014)

Nesses excertos, é possível observar o recebimento positivo do conteúdo do PP por parte do D-EA, já que há neles ${ }^{11}$ dois adjetivos de mesma origem (interessante/interessada), ambos precedidos por um advérbio intensificador ("muy"), o qual dá ênfase ao discurso de aceitação do texto do PP produzido pelo P-IF. No entanto, podemos notar um deslocamento da posição do sujeito, que no segundo e-mail está marcado pela primeira pessoa do plural (e não mais do singular), o que faz com que o 
interesse demonstrado deixe de ser pessoalizado e venha a estar constituído da avaliação de um grupo ("hemos estado analizando tu propuesta"). Essa pode ser uma estratégia discursiva que concede força ao posicionamento do D-EA sobre o PP. Além disso, outro recurso que confere eficácia aos argumentos do D-EA é o fato de incluir, para além do pessoal e do grupal, um terceiro "avaliador" da proposta: a instituição.

É também o professor quem dá o primeiro passo para a construção do texto que constituirá o Convênio interinstitucional. Tal passo constitui-se do pedido de que o D-EA envie o "modelo" de convênio de que dispõe ${ }^{12}$ e da exigência de que o D-EA assine o Convênio para que este possa ser registrado no Brasil posteriormente. Essa exigência confere outro tom à pragmática da conversa e gera uma reação do interlocutor do e-mail. Retomaremos esse ponto mais adiante.

Neste momento, queremos dar realce à função do professor-educador como um acelerador no que concerne ao andamento da construção do Convênio. Diante da ausência de resposta imediata do D-EA, nosso policy maker reenvia o e-mail em que pede um "modelo" de convênio e reitera que as assinaturas dos responsáveis da EA são essenciais para validar o documento. Cerca de uma semana depois de receber o dito modelo, o P-IF reencaminha ao D-EA o Convênio final (uma reedição do "modelo" enviado). Mas, novamente passados alguns dias sem o retorno do D-EA, o proponente do PP age com a intenção de dar agilidade (já que o PP fazia parte de seu projeto de doutorado e os trâmites burocráticos caminhavam a passos lentos dentro da instituição) à finalização das tramitações e à aceitação do Convênio por parte do D-EA, enviando-lhe o documento outra vez.

Outro episódio que gostaríamos de destacar diz respeito a uma cláusula do Convênio enviado pelo P-IF que gerou contraposição do D-EA. $\mathrm{O}$ trecho que segue mostra a ressalva do D-EA sobre a referida cláusula:

Nuestro asesor legal nos aconseja que, dado que se trata de un acuerdo entre instituciones de dos países, no es conveniente establecer una prórroga de jurisdicción ni en Brasil ni en Argentina. Nunca agregamos esta cláusula en los intercambio que hemos realizado con Austria y Canadá. Si llegado el caso ocurriese algún inconveniente se recurrirá, como corresponde, al Derecho Ordinario o Normativa del derecho Internacional público y privado. Pero es reduntante aclararlo en el acuerdo porque es el procedimiento que se debe seguir a nivel internacional. ${ }^{13}$ (excerto de e-mail, 17 ago 2014) 
Há, nessa interlocução, uma negociação entre as partes interessadas na formalização do Convênio, já que é no conteúdo desse texto que ficam assentadas as condições de um amplo acordo interinstitucional, que estabelece as fronteiras do que é ou não é legalmente aceito em termos de concretização do evento denominado intercâmbio. A análise do fragmento mostra-nos que o D-EA recorre ao uso da primeira pessoa do plural, agora com o objetivo de ancorar seus argumentos nos de uma autoridade ("asesor legal") no quesito em disputa. Ademais, argumenta que, em experiências político-educativas prévias ("con Austria y Canadá"), estabelecer tal cláusula nunca foi necessário ("Nunca agregamos esta cláusula"). Reafirmando seu entendimento e sua postura diante do caso em negociação, o D-EA é ainda mais incisivo ao dizer que há instância específica ("se recurrirá, como corresponde") para solucionar as celeumas que pudessem decorrer do Convênio e que, portanto, seria "redundante aclararlo en el acuerdo".

Em resposta ao persuasivo questionamento do D-EA, o P-IF reporta-se assim:

En cuanto a la última cláusula, la voy a sacar del documento. Así como ustedes, entiendo que no se puede establecer jurisdicción en ninguno de los países por tratarse de un acuerdo internacional. Lo hice, unicamente, porque tenía en manos un acuerdo que tenemos con una universidad chilena (para los cursos superiores) y en él se establece el Foro de la ciudad como responsable por dirimir eventuales problemas. Cuando lo tenga listo (mañana, probablemente), te lo enviaré y trataré del tema con la que, juntamente conmigo, es la responsable actual por el intercambio en el campus, a ver si nos ponemos todos de acuerdo con el contenido del documento y si lo podemos firmar. ${ }^{14}$ (excerto de e-mail, 17 ago 2014)

Ao concordar com o argumento do D-EA sobre a escolha inadequada de um fórum brasileiro para dirimir casos omissos aos previstos no Convênio, o P-IF tenta equilibrar a balança dos conflitos, optando por arriscar-se com o texto que estava construindo. O P-IF toma uma importante decisão como policy maker ao optar por retirar a cláusula do Convênio ("la voy a sacar del documento") e mostra, destarte, certo consenso ("Así como ustedes, entiendo") entre os interessados na elaboração do texto. Também notamos o esforço do P-IF em levar adiante o Convênio, fazendo com que os envolvidos cheguem a um entendimento comum ("a ver si nos ponemos todos de acuerdo"). 
É interessante observar, ainda, o trabalho coletivo de construção política (BALL, 2009), pois há outros atores sociais que estão imiscuídos no Contexto da Produção de Texto ("la responsable actual por el intercambio en el campus"). Nesse sentido, é necessário dizer que, embora o policy maker tenha de enfrentar sozinho certas fases do processo, em outras ele necessita agregar parceiros com vistas a levar adiante esse processo.

Contudo, a partir do trecho "Lo hice, unicamente, porque tenía en manos un acuerdo que tenemos con una universidad chilena", é possível ver que o P-IF se justifica sobre a presença daquela cláusula. Isso pode ser interpretado desde três vieses: a) o Contexto da Influência (MAINARDES, 2006) atuando sobre o CPT (acordos anteriores do IF influenciam a composição dos textos de um novo acordo), b) a necessidade de amenizar os conflitos gerados pela cláusula (delegar à presença da cláusula uma justificativa externa ao produtor do texto), c) usar de um artifício de mesmo peso para embasar a justificativa (assim como na EA, o IF também tem experiências prévias de acordos interinstitucionais) que respalda os movimentos iniciados pelo P-IF.

O professor tenta negociar, ainda, o cronograma que aparecerá no TA, com vistas a ampliar as possibilidades de atividades acadêmicas e culturais que seriam vivenciadas pelos alunos:

(...) te hago dos nuevas propuestas, a ver qué me decís: sería posible visitar un establecimiento más? Lo haríamos el primer día a la tarde (27.10). y/o no habría posibilidad de encajar, en alguno de los días, un paseo por la capital, incluyendo a una parte de la Universidad? ${ }^{15}$ (excerto de e-mail, 6 set 2014)

A isso, o D-EA responde de tal modo que parece estar disposto a negociar as solicitações do P-IF. Ele diz:

Con respecto a la visita a los establecimientos, éstos serán dos, pero si ustedes nos piden una tercer visita no hay inconvenientes, podemos conseguirla y llevarla a cabo el día lunes por la tarde.

Para realizar la visita a la capital se necesita un día entero, ya que nos encontramos a $289 \mathrm{~km}$ de distancia. Son, entre ida y vuelta, 7 horas de viaje cono mínimo. No sé cuál es la ruta que ustedes han planeado pero sería conveniente para ustedes realizar dicha visita en su viaje de paso cuando emprendan el regreso a Brasil. En ese caso deberían partir de nuestra ciudad el viernes por la mañana, visitar la capital y desde allí partir hacia Brasil. ${ }^{16}$ (excerto de e-mail, 8 set 2014) 
Como podemos notar, o cronograma que constaria no TA foi bastante negociado. Há certo equilíbrio entre as partes, uma vez que aquilo que é requerido por uma, parece ser atendido pela outra. O P-IF solicita que seja visitado mais do que um estabelecimento da área técnica dos alunos viajantes. Essa petição é corroborada pelo D-EA (“estos serán dos”), que se mostra aberto a incluir, igualmente, outros estabelecimentos no roteiro de saídas a campo ("si ustedes nos piden una tercer visita, no hay inconvenientes"). Também, ainda que não perceba facilidade em estender a viagem dos alunos brasileiros à capital do estado argentino, onde está localizada a EA, devido à distância entre elas ("para realizar la visita a la capital se necesita un día entero"), consente em que o passeio possa ser feito, desde que haja certa organização para tal.

Queremos retomar a situação das assinaturas, que havíamos deixado em suspenso, e o valor que têm as experiências precedentes na formalização do TA do intercâmbio. O D-EA recorre aos acordos prévios para defender que desconhece o procedimento de que os anfitriões tenham que assinar os documentos primeiro. Como uma maneira de validar o que diz, revela que isso, até então, nunca havia causado problemas. Tanto é assim que a instituição já estava (nesses moldes) planejando o segundo intercâmbio com as escolas dos países mencionados anteriormente. O D-EA reporta-se como segue:

Estimado profesor: Estuve viendo los adjuntos que me enviaste. En principio te comento que nunca que hemos realizado nuestros intercambios con Canadá y Austria se nos ha exigido que firmemos en primer orden. La verdad es que no hemos tenido inconvenientes y ya vamos por el segundo intercambio con ellos. ${ }^{17}$ (excerto de e-mail, 12 out 2014)

Luego de haber revisado el documento anexo que me envias, mis autoridades superiores consideran que para firmarlo es necesario que le hagamos modificaciones, ya que deberíamos también estipular que el Instituto de Brasil se compromete, en un acto de reciprocidad, a recibir a posteriori a nuestros alumnos y docentes en Brasil, y brindarles alojamiento, comida (que serán 4 y no tres: desayuno, almuerzo, merienda y cena) y traslados internos (de esto nosotros nos haremos cargo cuando ustedes estén en nuestra ciudad). El Instituto también debería comprometerse a organizar talleres y salidas similares a las que se llevarán a cabo en Argentina. ${ }^{18}$ (excerto de e-mail, 12 out 2014) 
Outro recurso que se repete é o apoio do D-EA nas palavras de outro, sendo este outro supostamente mais do que uma só pessoa e com maior autoridade sobre o assunto em pauta ("mis autoridades superiores"). O D-EA exige, ademais, que sejam feitas algumas modificações no TA, a fim de estipular, por escrito, o compromisso do IF em oferecer atividades similares aos alunos argentinos, em contrapartida àquelas que seriam efetivadas durante a visita dos alunos brasileiros à EA. As determinações feitas pelo D-EA sugerem certa precaução a respeito da experiência de internacionalização e demonstram a necessidade da igualdade de direitos e deveres entre ambas as instituições.

Entretanto, o P-IF posiciona-se acerca dos requerimentos do D-EA, após ter buscado a ajuda de outros membros (também supostamente superiores), colegas de instituição. Ao mesmo tempo, explicita as "regras do jogo" burocrático em relação aos textos políticos para acordos educativos internacionais dentro do IF quando expõe a diferença entre um texto-convênio e um texto-anexo (TA):

En cuanto al ANEXO, te digo lo que me dijo el Pro-rector Adjunto de Extensión a mí: allí estaría todo lo relacionado al viaje nuestro. Cuando ustedes vengan a Brasil, se hace un nuevo ANEXO en el que se describe solamente lo que dice respecto al viaje de ustedes. También me dijo que el Convenio, que es el documento más amplio, estipula que uno de los objetivos es "un intercambio entre alumnos y profesores de ambas instituciones" y que la palabra "intercambio" por si sola representa tanto nuestra salida a Argentina, como la venida de ustedes a Brasil. Los detalles se especificarían en los ANEXOS. El ANEXO lo construí yo, en base a un modelo del que el instituto disponde. La cuestión de que sean cuatro las comidas y no tres, es solo hacer la alteración necesaria en el documento antes de firmarlo. ${ }^{19}$ (excerto de e-mail, 15 ago 2014)

O P-IF sustenta seu argumento, reportando as palavras da autoridade, baseando-se na escolha terminológica ("intercambio"). Provavelmente, o D-EA tenha lido o texto na íntegra, mas o modo como o interpretou, isto é, as elucubrações da transição do Contexto da Produção de Texto para o Contexto da Prática (BALL, 2009), foi diferente da "atividade criativa" dos educadores brasileiros.

Posteriormente, o P-IF reconhece que também o TA (além do Convênio) foi elaborado com base em um texto de outro documento (com função similar dentro do IF), embora o trabalho de adequação dos propó- 
sitos tenha ficado a seu cargo. Nesse sentido, a atuação do professor-policy maker revela que a construção que faz dos textos está arraigada em práticas culturais de sua instituição, das quais toma conhecimento e que, justamente por essa razão, o conteúdo dos documentos não é aleatório. Entretanto, ele expressa que é autor de suas próprias construções e que tem o poder de escolher as assertivas que irão figurar (ou não) no texto do TA.

\section{Considerações sobre o caso analisado}

Conseguimos elucidar, de forma ampla, como se dá o Contexto da Produção de Texto numa política linguística específica. Voltemos, agora, a nossa primeira pergunta: Quando se inicia a construção dos textos da política e quem participa dessa construção? No nosso caso, a construção dos textos começa com uma atividade individual, de interesses pessoais e profissionais de um professor-pesquisador. Essa construção materializa-se, primeiramente, no Projeto Pedagógico de uma experiência de internacionalização. Mas esse texto primário passa a dar origem a textos secundários, como o Convênio e o Termo Aditivo. Os principais participantes da consolidação dos textos são o P-IF e o D-EA, embora haja atores no pano de fundo dessa conjuntura política, tais como assessores jurídicos, diretores de extensão e, até mesmo, a instituição, representada na voz de seus membros.

Como pudemos observar, a construção dos textos não é um processo unidirecional, em que todos os agentes compartilham ideias e valores. Ao contrário, como diz Ball (2009), a política é um campo de conflitos e lutas, em que entram em jogo diversos interesses. A interlocução no Contexto da Produção de Textos não foi, de modo algum, linear, já que aqueles engajados nessa tarefa discutem suas perspectivas e, consequentemente, ocasionam idas e vindas para a construção dos textos. Lembramos, conforme Stephen Ball (2009), que as políticas educativas são um esforço coletivo. No entanto, isso não destitui o papel de protagonismo desse professor, que deu o pontapé inicial na proposta da política linguística, partindo de sua posição de base (MENKEN; GARCÍA, 2010).

Mas, como quer a nossa segunda pergunta de pesquisa, "houve a intenção de buscar consensos na produção dos textos e esse objetivo foi alcançado?" Apesar das disputas, em determinados momentos, houve a busca por consenso na produção dos textos. O consenso veio precedido dessas disputas. Dado que ambos os representantes das instituições envolvidas estavam interessados no intercâmbio como uma via de mão 
dupla para a internacionalização do conhecimento, era necessário que se chegasse a um acordo válido para ambos. O professor destaca-se por ter atuado fortemente no papel de negociador em busca da harmonização dos textos materializados.

Chegamos, por fim, a nossa terceira pergunta: Quais são as ideias predominantes nos textos construídos e que propósitos e valores elas representam? Ainda que não tenhamos analisado os textos propriamente ditos, podemos presumir, a partir dos dados apresentados, que o Projeto Pedagógico apresenta, de uma visão unilateral (dada a origem do documento), uma projeção daquilo que poderia/deveria ser desenvolvido como atividade de intercâmbio e quais benefícios esse evento traria aos participantes. O Convênio, por sua vez, estabelece formalmente as bases sobre as quais as atividades teriam de ser desenvolvidas, as premissas e as implicações de tais tarefas bilateralmente, isto é, para as duas instituições envolvidas. Já o Termo Aditivo configura-se como uma extensão do Convênio, específica para cada ocasião em que se põem em prática os acordos estipulados.

Observar o papel do professor como um policy maker pode ser encorajador, principalmente quando se mostram resultados positivos, como os que apresentamos aqui. Dizemos encorajador, pois o professor pode se sentir motivado para tomar iniciativas de cunho político-linguístico na microesfera escolar. Ao mesmo tempo, é uma tarefa desafiadora, pois ele terá de sair de sua posição costumeira e encarar os percalços que o agir político poderá apresentar. 


\section{THE TEACHER AS A POLICY MAKER: THE CONTEXT OF TEXT PRODUCTION IN A KNOWLEDGE INTERNATIO- NALIZATION PROJECT FOR TECHNOLOGICAL HIGH- -SCHOOL STUDENTS}

\section{ABSTRACT \\ In this paper, we aim to present the process of texts construction during a knowledge internationalization project conceived of for high-school students from a technological school. It is a case study guided by the theory of language education policies, which focu- ses on the teacher's role as an agent of the school micro context (MENKEN; GARCÍA, 2010) and the Policy Cycle method of analysis (BALL; BOWE, 1992). The results show how language policies (collective actions, dynamic and conflicting) may be hea- ded and led by a teacher, who is hierarchically inferior to her inter- locutors in terms of institutional position. \\ KEYWORDS: language education policies; agency; teacher; Po- licy Cycle.}

\section{REFERÊNCIAS}

BALL, Stephen. Palestra "The Policy Cycle/policy analysis". Programa de Pós-Graduação em Educação - PROPED/UERJ, 09/11/2009. Disponível em: <http:// www.ustream.tv/recorded/2522493>

CÁCERES, Glenda H. Políticas linguísticas em uma escola pública de ensino médio e tecnológico: a oferta de línguas estrangeiras. Trab. linguist. apl. [online]. 2014, v.53, n.1, pp. 103-129. ISSN 0103-1813. Disponível em: <http://www. scielo.br/pdf/tla/v53n1/v53n1a06.pdf>

COOPER, Robert L. Language planning and social change. Cambridge University Press: New York, 1979.

KAPLAN, Robert; BALDAUF JR., Robert. Language planning: from practice 
to theory. Clevedon, UK: Multilingual Matters, 1997.

MCCARTY, Theresa L. Introducing ethnography and language policy. In: Ethnography and language policy. Routledge: New York, 2011. pp. $1-28$

MAINARDES, Jefferson. Abordagem do ciclo de políticas: uma contribuição para a análise de políticas educacionais. Educação \& Sociedade, Campinas, v. 27, n. 94, pp. 47-69, jan./abr. 2006. Disponível em: <http://www.scielo.br/pdf/es/ v27n94/a03v27n94.pdf>

MENKEN, Kate; GARCÍA, Ofelia. Stirring the onion: educators and the dynamic of language education policies (looking ahead). In: Negotiating language policies in schools: educators as policymakers. Routledge: New York, 2010. pp. 249-261

RICENTO, Thomas. Theoretical perspectives in language policy: an overview. In: (ed.) An introduction to language policy: theory and method. Blackwell: Malden, MA, 2006. pp. 3-9

STAKE, Robert E. Case studies. In: DENZIN, Norman K; LINCOLN, Yvonna S. (eds.) Strategies of qualitative inquiry. 2 ed. SAGE: Thousand Oaks, CA, 2003. pp. 134-164

\section{NOTAS}

${ }^{1}$ Uma primeira versão deste trabalho foi apresentada em comunicação oral individual no I Congreso Latinoamericano de Glotopolítica, ocorrido nos dias 13 e 14 de agosto de 2015, na Universidad de Chile (Chile).

${ }^{2}$ Este texto está construído sobre uma parte dos dados que foram gerados na construção de minha tese de doutorado. Este recorte do corpus, contudo, não é objeto central de análise na tese.

${ }^{3} \mathrm{O}$ CSF incidiu enormemente no direcionamento das línguas adicionais (espanhol e inglês) ensinadas na escola de que procede esta pesquisa. Não se tratou, no entanto, de uma política linguística explícita a incidência desse programa nas práticas escolares e talvez tenha sido até uma política linguística inconsciente por parte das autoridades escolares. A Lei 11.161/2005, que determina a oferta obrigatória de língua espanhola no Ensino Médio faz, igualmente, parte do cenário investigado, embora sua presença nele não se deva exclusivamente à Lei em si (ver CÁCERES, 2014). Já a Lei 11.684/2008, que alterou o Art. 36 da LDB/1996, incluindo obrigatoriamente as disciplinas de Filosofia e Sociologia no currículo 
do Ensino Médio não foi suficiente para evitar as citadas manifestações. Políticas como as mencionadas nesta nota nem sempre são seguidas à risca, já que as ambiguidades ou espaços que as permeiam permitem múltiplas interpretações. Muitas vezes, os agentes re-contextualizam (imprimem o seu olhar) discursos - orais ou escritos - já produzidos (BALL, 2009).

${ }^{4}$ Adotamos a nomenclatura Políticas Linguísticas neste texto, em detrimento de diversas outras existentes para a mesma área de estudos, que variam alguns matizes, mas que mantêm o escopo investigativo no planejamento e nas ações relacionadas à língua e ao vínculo desta com alguma esfera social.

${ }^{5}$ Jeferson Mainardes é professor e pesquisador na Universidade Estadual de Ponta Grossa, Brasil. O professor tem estudado extensamente as obras de Stephen Ball e publicado diversos textos (inclusive como coautor junto ao sociólogo) sobre tais obras.

${ }^{6}$ Um quadro maior que o outro não representa, na Figura 1, as dimensões dos valores de seus conteúdos, isto é, um quadro maior não quer significar algo mais relevante que o que está descrito em um quadro menor. Na verdade, qualquer parte do processo é igualmente importante para o efeito da política. Como dissemos, é a leitura (interpretação) de cada um dos atores que fará variar o valor de cada passo e, por isso, um item bastante significativo para um deles pode significar pouco ou nada para o outro.

${ }^{7}$ Os excertos de texto que aparecem nesta seção contêm palavras em itálico, que substituem as originais para preservar o anonimato dos participantes da pesquisa, e palavras sublinhadas, que são grifos nossos a respeito do conteúdo dos textos. Com exceção dos itálicos, os textos foram preservados conforme figuram originalmente.

${ }^{8} \mathrm{~A}$ fim de distanciar-me dos dados e fazer o exercício do ponto de vista do pesquisador, refiro a mim como "professor", masculino e singular, indicando, ainda, que outros professores também poderiam ser o ator social que cumpre meus papéis revelados na análise.

${ }^{9}$ Estive analisando a tua proposta e me parece muito interessante.

${ }^{10}$ Estimado professor: estivemos analisando a tua proposta mais detalhadamente e, na verdade, nossa instituição está muito interessada em concretizar o intercâmbio que nos propões.

${ }^{11}$ A segunda inserção do D-EA é uma nova iniciativa sua, já que o e-mail anterior ainda não havia sido respondido pelo P-IF.

${ }^{12}$ Essa solicitação procedeu do conhecimento do D-IF da existência prévia de intercâmbios educativos entre a EA e outras duas instituições de ensino. Saber de 
tais intercâmbios faz parte, no CP em questão, do Contexto da Influência, já que foi um argumento usado pelo professor policy maker para dar credibilidade à EA, a fim de convencer o D-IF a manter viva a proposta de internacionalização (a qual, em muitos momentos, esteve ameaçada de não ser concretizada).

${ }^{13}$ Nosso assessor legal nos aconselha que, dado que se trata de um acordo entre instituições de dois países, não é conveniente estabelecer um fórum para a solução de problemas nem no Brasil, nem na Argentina. Nunca adicionamos essa cláusula nos intercâmbios que realizamos com a Áustria e o Canadá. Se acaso ocorresse algum problema se recorrerá, como deve ser, ao Direito Ordinário ou Normas de direito Internacional público e privado. Mas, é redundante esclarecer no acordo porque é o procedimento que se deve seguir em nível internacional.

${ }^{14}$ Quanto à última cláusula, vou retirá-la do documento. Assim como vocês, entendo que não se pode estabelecer um fórum em nenhum dos países ao se tratar de um acordo internacional. Fiz isso, unicamente, porque tinha em mãos um acordo que temos com uma universidade chilena (para os cursos superiores) e nele se estabelece o Fórum da cidade como responsável por dirimir eventuais problemas. Quando tiver o documento pronto (amanhã, provavelmente), te mandarei e tratarei do assunto com quem, juntamente comigo, é a responsável atual pelo intercâmbio no Campus, para ver se todos concordamos com o conteúdo do documento e se podemos assiná-lo.

${ }^{15}$ (...) te faço duas propostas novas, vamos ver o que achas: seria possível visitar mais um estabelecimento? Faríamos a visita no primeiro dia à tarde (27.10) e/ou não haveria possibilidade de encaixar, em algum dos dias, um passeio pela capital, incluindo uma parte da Universidade?

${ }^{16}$ A respeito da visita aos estabelecimentos, estas seriam duas, mas se vocês querem uma terceira visita, não tem problema, podemos consegui-la e realizá-la na segunda à tarde. Para realizar a visita até a capital é necessário um dia inteiro, já que estamos a $289 \mathrm{~km}$ de distância. São, entre ida e volta, 7 horas de viagem no mínimo. Não sei qual é o trajeto que vocês planejaram, mas seria conveniente para vocês realizar essa visita na sua viagem de volta, a caminho do Brasil. Nesse caso deveriam sair da nossa cidade na sexta de manhã, visitar a capital e de lá, ir para o Brasil.

${ }^{17}$ Prezado professor: estive vendo os anexos que me enviaste. Em princípio, comento que nunca, quando realizamos nossos intercâmbios com o Canadá e a Áustria nos exigiram que assinássemos primeiro. $\mathrm{Na}$ verdade, não tivemos problemas e vamos concretizar o segundo intercâmbio com eles.

${ }^{18}$ Após ter revisado o documento anexo que me envias, minhas autoridades superiores consideram que para assiná-lo é necessário que façamos modificações já 
que deveríamos também estipular que o Instituto do Brasil se compromete, num ato de reciprocidade, a receber a posteriori os nossos alunos e professores no Brasil, e fornecer-lhes hospedagem, refeições (que serão 4 e não três: café da manhã, almoço, lanche e janta) e traslados internos (disso nós nos encarregaremos quando vocês estiverem na nossa cidade). O Instituto também deveria se comprometer a organizar oficinas e passeios similares aos que acontecerão na Argentina.

${ }^{19}$ Quanto ao ANEXO, te digo o que me disse o Pró-reitor Adjunto de Extensão: ali estaria tudo que se relaciona à nossa viagem. Quando vocês vierem ao Brasil, faremos um novo ANEXO no qual se descreve somente o que diz respeito à viagem de vocês. Ele também me disse que o Convênio, que é o documento mais amplo, estipula que um dos objetivos é "um intercâmbio entre alunos e professores de ambas as instituições" e que a palavra "intercâmbio" por si só representa tanto a nossa ida à Argentina quanto a vinda de vocês ao Brasil. Os detalhes seriam especificados nos ANEXOS. O ANEXO fui eu que construí, baseado num modelo de que o instituto dispõe. A questão de que sejam quatro refeições e não três, é só fazer a alteração necessária no documento antes de assiná-lo.

Recebido em: 15 de janeiro de 2016

Aceito em: 25 de abril de 2016 